J. Lake Sci. (湖泊科学), 2012, 24(3):327-333

http: //www.jlakes.org. E-mail : jlakes@niglas.ac.cn

(C) 2012 by Journal of Lake Sciences

\title{
太湖流域重污染区主要水污染物总量控制
}

\author{
边 博 $^{1}$, 夏明芳 ${ }^{2}$, 王志良 ${ }^{1}$, 尤本胜 ${ }^{1}$, 逢 勇 $^{3}$, 常闻捷 ${ }^{1}$, 王伟霞 ${ }^{1}$, 蔡安娟 ${ }^{1}$ \\ ( 1 : 江苏省环境科学研究院,南京 210036$)$ \\ (2: 江苏省太湖水污染防治办公室,南京 210024) \\ (3:河海大学,南京 210098$)$
}

摘 要: 太湖流域产业、人口集聚,水环境污染已经成为整个太湖流域经济可持续发展的制约因素之一, 为解决经济发展 引起的环境问题, 对污染物排放实行总量控制至关重要. 为此以太湖流域梅梁湾、竺山湾上游集水区域 (重污染区) 为研 究区域,全面调查区域社会经济、产业结构、土地利用以及各类污染源现状,构建重污染区套网格水文、水质数学模型,计 算区域水环境容量与污染物削减量,依据水功能区划与水域面积分配到各镇(街道),确定重污染区以镇(街道)级为基本 单位的分阶段总量控制目标, 制订主要污染物控制与负荷削减综合系统方案, 提出 2015 年各类污染源重点工程措施, 方 案实施后区域河网水质平均达标率达 $80 \%$,为太湖流域水环境管理提供技术支撑.

关键词: 太湖流域;重污染区;水环境容量;总量控制;削减方案

\section{Total amount control of main water pollutants in seriously polluted area of Taihu Basin}

BIAN Bo $^{1}$, XIA Mingfang ${ }^{2}$, WANG Zhiliang ${ }^{1}$, YOU Bensheng ${ }^{1}$, PANG Yong ${ }^{3}$, CHANG Wenjie ${ }^{1}$, WANG Weixia $^{1} \&$ CAI Anjuan ${ }^{1}$

(1: Jiangsu Provincial Academy of Environmental Science, Nanjing 210036, P. R. China)

(2: Jiangsu Provincial General Office of Lake Taihu Water Pollution Prevention and Control, Nanjing 210024, P. R. China)

(3: Hohai University, Nanjing 210098, P. R. China)

Abstract: As industry and population increase rapidly, the pollution of water environment has become a main factor influencing the sustainability of economic development in Taihu Basin. In order to achieve the integrated development in economy and environment protection, the implementation of total quantity control of pollutant discharge is important. In the study areas of Meiliang Bay and Zhushan Bay, we made a comprehensive research on situations of area economy, industrial structure, landuse and status of pollutant sources. Nested grid hydrology model and water quality model have been established to calculate regional water environmental capacity and pollutant reduction. Based on the water function and water areas, the water environmental capacity was assigned to every town ( settlement). Thus the aim of total quantity control in different periods of each town and the plan of control and reduction of main pollutants have been established. The solution of pollutant control of each source in different periods has been proposed. Qualifying rate of regional water quality in river network areas will reach $80 \%$ by the year of 2015 after the plan implemented. The plan will provide technical support for the water environmental management of Taihu Basin.

Keywords: Taihu Basin; seriously polluted area; water environment capacity; total amount control; reduction plans

太湖流域位于长江三角洲核心地区, 区域内人口积聚、工业密集, 流域水环境质量日益恶化,太湖西北 部地区污染尤为严重,该区域总面积 $5272 \mathrm{~km}^{2}$, 占太湖流域的 $14 \%$, 基本涵盖了太湖流域上游主要人湖河 流, 河网区水质达标率仅为 $17 \%$, 占太湖人湖污染物通量的 $80 \%$ 左右 ${ }^{[1]}$, 是影响太湖湖体, 特别是梅梁湾、 竺山湾水质的主要区域,是太湖流域的重污染区. 区域污染产业比重大、水污染物排放量居高不下,跨行政 区域的上下游污染源削减和总量控制方面均存在较为突出的矛盾. 因此开展重污染区水污染物总量研究,

* 国家水体污染控制与治理科技重大专项项目(2008ZX07101-002) 和江苏省自然科学基金项目 (BK2010091) 联合资 助. 2011-08-16 收稿;2011-10-11 收修改稿. 边博,男,1978 年生,博士, 高工;E-mail:bianbo1@ 163.com. 
不仅对该地区具有现实意义,而且对整个太湖流域都具有重要作用.

流域是一个完整的水文循环单元,也是资源供求、人与自然、发展与水环境保护的矛盾冲突集中体. 水 环境问题是一个涉及土地利用、上下游相互关系、多种水体类型、多种污染类型的综合性问题,所以基于流 域尺度进行水环境管理势在必行 ${ }^{[2]}$. 美国在 1980s 提出流域污染治理则强调抓住重点河流、重点流域,逐条 河流治理和每个流域整治,强调流域生态系统的整体治理 ${ }^{[3]}$,其中的美国日最大排放负荷 (TMDL) 计划是在 满足水质标准的条件下确定总量, 总量控制指标已多达 9 项 (沉积物、病原体、重金属、溶解氧、水温、 $\mathrm{pH} 、$ 杀 虫剂、采和有机物 $),$ 允许排污量可根据上述指标在各季节的差异来确定,实现季节总量控制 ${ }^{[4]}$,使得美国的 水环境污染控制取得明显成效. 2000 年欧盟《水框架指令》(WFD) 强调从流域尺度综合考虑水资源、水利用 方式和价值、生态因素、治理措施以及不同层次决策者等诸多因素,通过质量标准反演法,制定基于水质标 准的排放限值, 实现污染物的控制.

近年来,我国在控制污染、削减污染物排放总量方面取得些进展,在总量指标篮选、排放总量核算、水环 境功能区划、水环境容量计算、总量指标分配与污染物削减方案等方面展开研究,将总量控制技术与水污染 防治规划相结合, 逐步形成了以污染物目标总量控制技术为主,容量总量控制和行业总量控制为辅的水质 管理技术体系 ${ }^{[5]}$. 基于该技术体系,制定了“三河” (淮河、海河、辽河)，“三湖” (太湖、巢湖、滇池) 水污染防 治规划 ${ }^{[6-8]}$. 但是仍然没有达到控制污染源、改善水质的效果, 尤其是太湖人湖污染负荷居高不下, 总量控制 与水质改善脱节, 总量控制缺乏显著实效, 难以满足太湖流域水环境管理的迫切需求 ${ }^{[9-10]}$. 如何科学、合理地 在各种污染源以及污染单位之间分配允许排放污染物量, 提出公平科学的分配方法, 确定更加有效的污染 控制方案, 成为总量控制的核心问题 ${ }^{[11]}$. 因此以梅梁湾、竺山湾上游集水区域 (太湖流域重污染区) 为研究 区域,通过综合调查,查清各类污染源排放和水质情况,建立重污染区水质水量耦合水环境数学模型,测算 水环境容量并科学分配,确定分阶段总量控制目标,制定主要污染物控制综合方案,形成重污染区污染源综 合控制技术体系,为太湖流域水环境管理提供技术支撑.

\section{1 研究区概况}

太湖流域重污染区主要指太湖竺山湾和梅梁湾的上游汇水区域,涉及无锡市南长、崇安、北塘、惠山、新 区、滨湖 6 区和宜兴市, 以及常州市钟楼、天宁、戚墅堰、新北和武进 5 区, 共 41 个镇,56 个街道. 研究区域总 面积 $5272 \mathrm{~km}^{2}$, 占太湖流域的 $14 \% .2007$ 年研究区总人口 $744 \times 10^{4}$ 人, 占太湖流域的 $21 \%$, 农村人口 $290 \times$ $10^{4}$ 人; 人口密度达 1412 人 $/ \mathrm{km}^{2}$, 为太湖流域的 1.2 倍; GDP 总量 $3437 \times 10^{8}$ 元, 人均 GDP $4.6 \times 10^{4}$ 元, 为太 湖流域的 0.97 倍; 三产比例为 $1: 28: 21$, 总体呈 “ 231 ” 结构 ${ }^{[12-14]}$; 农用地类型主要有旱地、水田、茶园、桑园、 果园 5 种,农用地总面积占土地总面积的 $40 \%$ ，建设用地占土地总面积的 $33.28 \%$.

\section{2 计算方法}

\section{1 水环境模型构建及水环境容量计算}

在太湖流域套网格模型计算提供的设计水文条件和边界条件的基础上,根据重污染区河网分布特征, 将天然河网进行合并、概化; 并利用面源产污规律实验结果, 参数化后嵌人重污染区水环境数学模型, 建立 考虑点源及面源共同影响的太湖流域及重污染区分布式污染负荷模型,构建完整的太湖流域重污染区污染 物源头发生一河网传输一人湖负荷水量水质耦合水环境数学模型. 模型的研究区域主要为常州市区、武进区、 无锡惠山区、滨湖区西部和宜兴北部,模型计算范围的边界北至京杭大运河,南至东㳄和西㳄,西至滆湖,东 至梅梁湾和笈山湾 (图 1).

\section{2 水环境容量计算及分配方法}

根据确定的边界水文条件,利用研究区域河网水环境数学模型,计算出研究区域最小空间单元和最小 时间单元的水环境容量值,再根据公式汇总出研究区域的水环境容量值:

$$
W_{\text {水环境容量 }}=\alpha_{i j} \sum_{i=1}^{n} \sum_{j=1}^{m} Q_{0 i j}\left(C_{s i j}-C_{0 i j}\right)+K V_{i j} C_{s i j}
$$

式中, $\alpha_{i j}$ 为不均匀系数; $0<\alpha_{i j} \leqslant 1$; 河道越宽、水面越大, 则 $\alpha_{i j}$ 越小. 
影响控制单元水环境容量分配的主要因素 有两点:一是控制单元内水功能区划情况, 二是 控制单元的水域面积(图 2). 太湖流域平原河网 区水环境容量计算过程中, 以水功能区为最小计 算单元, 累加各功能区得到无锡市、常州市和宜 兴市三地市水环境容量总值, 将三地市容量分配 至 97 个镇 (街道). 考虑控制单元水功能区划并 基于遥感资料和 GIS 技术分析得到各镇区水域 面积, 采用水环境容量分配公式 (2) 和 (3) 进行 分配:

$$
\begin{gathered}
\alpha_{j}=\sum_{i=1}^{5}\left(S_{j} \frac{l_{i j}}{\sum_{i=1}^{5} l_{i j}} C_{s i}\right) / \sum_{i=1}^{5}\left(S \frac{l_{i}}{\sum_{i=1}^{5} l_{i}} C_{s i}\right) \\
W_{j}=\alpha \cdot W_{\text {总 }}
\end{gathered}
$$

式中, $\alpha_{i j}$ 为某镇 $j$ 占环境容量的权重; $W_{\text {总为研究 }}$ 区域总水环境容量; $W_{j}$ 为某镇 $j$ 的水环境容量; $C_{s i}$ 为 $i$ 类水水质标准; $S_{j}$ 为某镇 $j$ 的水域面积; $l_{i j}$ 为某镇 $j$ 的 $i$ 类水功能区总长; $S$ 为研究区域总的 水域面积; $l_{i}$ 为研究区域的 $i$ 类水功能区总长.

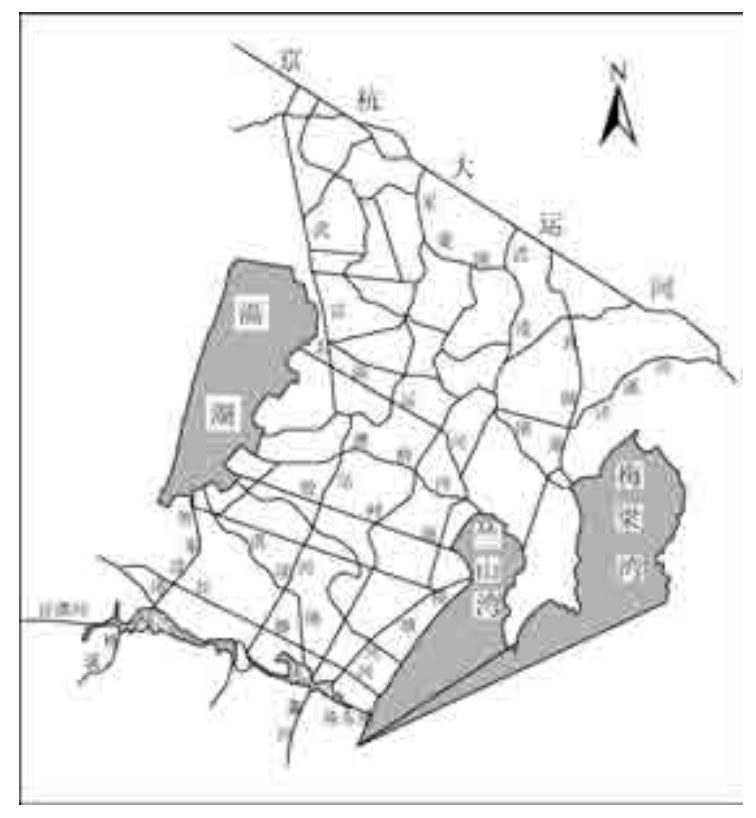

图 1 研究区域河网概化图

Fig. 1 The river network generalization graph of study area

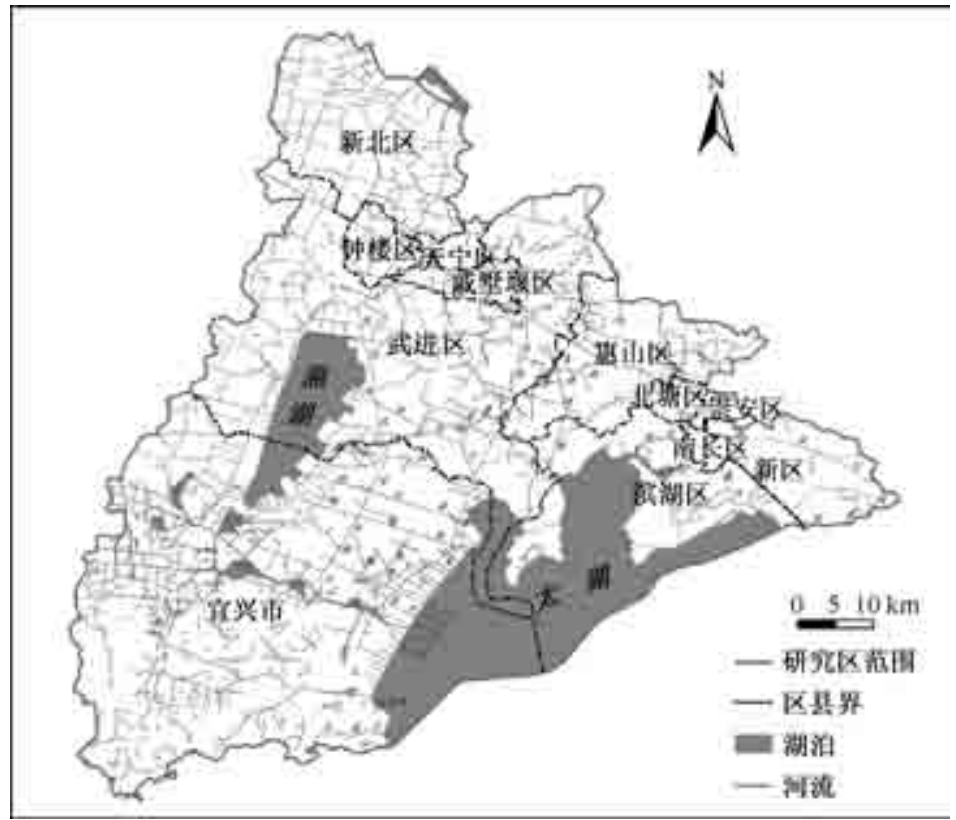

图 2 重污染区水域面积

Fig. 2 Water area of seriously polluted area

\section{3 污染源削减目标的分配与优化}

以最小投资取得最大治污效果为目标, 构建目标函数:

$$
\min Z=c_{1} x_{1}+c_{2} x_{2}+\cdots+c_{n} x_{n}=\sum_{i=1}^{n} c_{i} x_{i}
$$


式中, $Z$ 为投资额; $c$ 为费效比; $x$ 为减排效益. 设定约束条件:

$$
\sum_{j=1}^{n} x_{i j} \geqslant b_{i}
$$

式中, $x_{i j}$ 为第 $i$ 类污染源第 $j$ 类措施污染物减排效益, $b_{i}$ 为第 $i$ 类污染源减排效益.

以重污染区总量控制目标为总体约束, 结合地方经济发展、环境治理及太湖流域水污染治理的总体要 求, 确定各污染源不同治理措施的约束条件及不同情景的费用效益比,最终科学确定工业源、城镇生活源、 农村面源污染物最优削减目标.

\section{3 结果与讨论}

\section{1 水环境特征}

3.1 .1 污染源 以研究区各镇、街道为基本单元和 2007 年为基础年,详细调查了工业、城镇生活、农村生活 和农业面源四类污染源, 依据污染源普查、排污申报、环境统计中的基础数据,通过分类抽样调查与实地监 测, 田间单元实验与现场采样分析, 核实了各污染源数据, 对缺失的污染物数据进行校核和补充. 调查企业 11023 家,污染主要集中在无锡市惠山、新区、宜兴市以及常州新北、武进、天宁等地区. 区内主要有化工、印 染、钢铁、电镀、造纸和食品制造六大行业,纺织染整和化学工业污染较重; 农村生活污染主要集中在常州武 进区、新北区, 无锡惠山区、宜兴市等地; 面源污染主要集中在常州市武进、新北以及无锡惠山、宜兴市等地 区. 2007 年重污染区排放 COD、氨氮和总磷分别为 $11.06 \times 10^{4} \mathrm{t} 、 1.16 \times 10^{4} \mathrm{t}$ 和 $0.15 \times 10^{4} \mathrm{t}$, 排放量分别占 总排放量的 $44.33 \% 、 58.25 \%$ 和 $51.14 \%$ （图 3), 排放构成均以城镇生活源为主. 研究区共有城镇污水处理 厂 52 座,2007 年污水处理率约为 $67.5 \%, 2009$ 年处理率约提高到 $78.2 \%$.

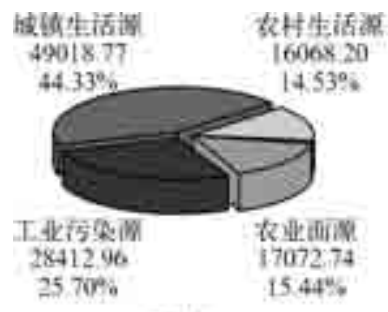

$\mathrm{COD} / \mathrm{t}$

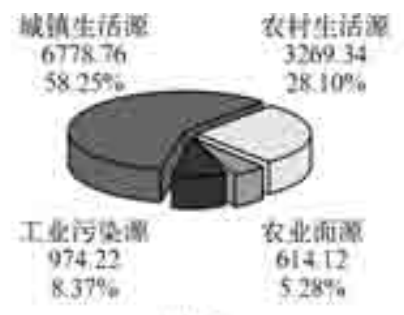

妾触/

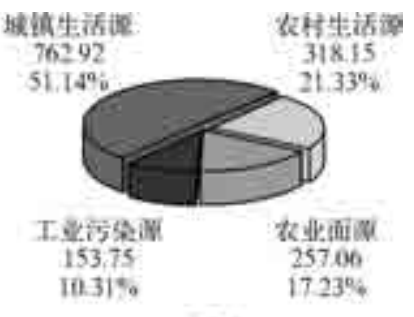

$\mathrm{TP}>\mathrm{t}$

图 3 重污染区各类污染源排放构成

Fig. 3 Composition of pollutant sources in seriously polluted area

3.1 .2 水质 重污染区水系共设有 55 个省控监测断面,其中 25 个为国控断面. 依据 COD、氨氮、TP 3 个水质 因子评价, 在 55 个省控水质监测断面中, 劣 $\mathrm{V}$ 类水质占 $67.27 \% 、 \mathrm{~V}$ 类占 $18.18 \%$ 、 $\mathrm{IV}$ 类占 $10.91 \%$ 、III 类占 $3.64 \%$. 主要污染因子为氨氮, 2009 年水质超标率均有所降低, 尤其是总磷超标率下降明显. 2007 年研究区 内 14 条主要人湖河流中有 8 条河流为劣 $\mathrm{V}$ 类水质、 3 条为 $\mathrm{V}$ 类水质 (陈东港、官渎港、洪巷港)、 2 条为 $\mathrm{IV}$ 类 水质 (大浦港、乌溪港) 、 1 条为 III 类水质 (大港河) ; 主要污染因子依次为氨氮、总磷和 $\mathrm{COD}_{\mathrm{Mn}}$.

\section{2 水环境容量计算及分配}

3.2 .1 重污染区水环境模型参数率定 2009 年开展了研究区水文水质同步监测实验, 共设置了 73 个监测点 位, 其中 23 处水文监测断面 (图 4), 水文监测频次每天 1 次, 监测因子为流量、流速、水深; 水质监测频次每 天 2 次, 监测因子为 $\mathrm{pH}$ 、水温、 $\mathrm{COD} 、 \mathrm{COD}_{\mathrm{Mn}}$ 、氨氮、 $\mathrm{TN} 、 \mathrm{TP}$, 部分断面加测 $\mathrm{BOD}_{5}$. 根据重污染区水文、水质同步 监测结果, 利用建立的重污染区河网数学模型, 率定得到的 COD、氨氮、TP 的降解系数分别为 $0.09 \sim 0.11$ 、 $0.05 \sim 0.07 、 0.04 \mathrm{~d}^{-1}$. 根据率定得到的参数, 利用重污染区水文、水质同步监测的结果, 采用重污染区河网 模型进行计算. 重污染区水量的计算平均值和实测值的相对误差在 $20 \%$ 左右, $\mathrm{COD}_{\mathrm{Cr}}$ 氨氮和总磷浓度的计 算值和实测值的相对误差分别为 $17 \% 、 16 \% 、 19 \%$, 四个主要因子的计算值和实测值的相对误差在 $20 \%$ 之 内, 说明建立的模型可应用于重污染区水环境容量计算. 


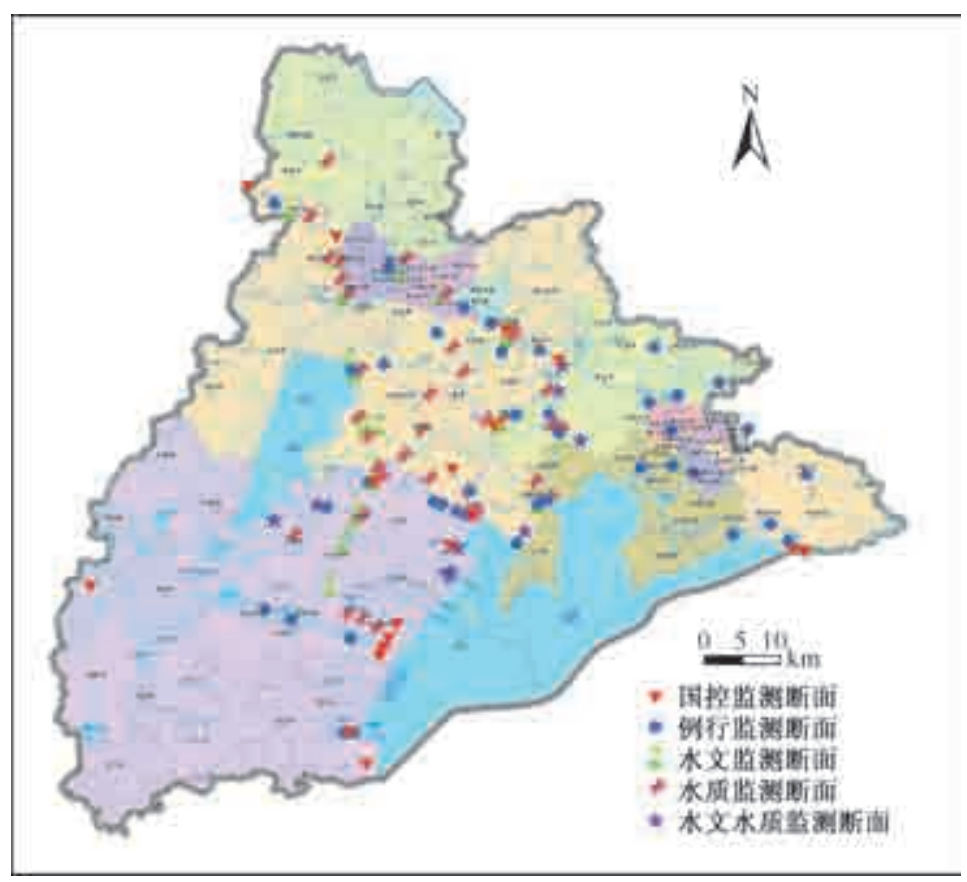

图 4 重污染区主要水系水质、水量监测断面布点

Fig. 4 Water quality and quantity monitoring points of the main river system in seriously polluted area

\section{2 .2 水环境容量计算和分配通过水文、水质同步监测得到} 的研究区污染物降解规律成果, 依据研究区河网水体水质目标, 考虑研究区的水文情势和水流特征, 采用构建非稳态水环境数 学模型计算建立了容量测算体系. 根据设计水文条件计算成果、 不均匀系数研究成果及重污染区 2015 年水环境功能区定位和 功能区划水质目标, 利用水环境容量计算公式计算出每个功能 区的水环境容量. 将研究区总量分配削减方案得出的污染物削 减率与研究区国控及省控断面的水质监测资料数据中断面水质 超标率进行对比分析, 验证研究区水环境容量计算结果的合理 性,若两者数据基本保持一致,则说明水环境容量计算结果基本 符合实际. 因为河流水质现状主要受上游来水水质及沿岸污染 物的影响, 当污染物人河量增加时, 河流的水质也将相应恶化. 因此, 当河流水质超标时, 污染物削减率随之增大, 污染物削减 率与断面水质超标率的相对误差小于 $20 \%$, 说明研究区水环境 容量计算结果合理 (图 5 ).

依据重污染区水环境容量分配方法, 以水环境功能区为基本单元, 以水环境功能区上、下界面或常规监 测断面作为节点, 根据重污染区 2010 年与 2020 年功能定位和功能区划水质目标, 将 2015 年重污染区 COD、 氨氮、总磷水环境容量值分别为 $6.2 \times 10^{4} \mathrm{t} 、 0.39 \times 10^{4} \mathrm{t} 、 400 \mathrm{t}$, 分配到 97 个镇(街道), 将重污染区的分镇人河量 与环境容量进行对比,得出重污染区现状条件下分镇总体达标情况,结果表明,2007 污染物排放现状条件 下,2015 年 COD、氨氮和总磷 3 项指标 97 个镇(街道) 中达标镇(街道) 的达标率最低为 $16.5 \%$, 最高的达标 率也不超过 50.0\%（表 1), 因此对于制定满足分镇总量达标情况下的各镇(街道)2015 年污染物削减方案 的污染物控制目标, 应在污染物负荷预测和对于重污染区的污染物排放现状进行污染潜力分析的基础上, 确定污染源控制与污染物减排综合系统方案分源污染物控制的优化目标, 然后进行分源削减. 
表 12015 年重污染区现状条件下 分镇总体达标情况

Tab. 1 Situation of each town reaching the standards under the condition of serious contamination in 2015

\begin{tabular}{lccc}
\hline 指标 & COD & 氨氮 & 总磷 \\
\hline 达标镇(街道)数 & 40 & 23 & 16 \\
达标率 $/ \%$ & 41.2 & 23.7 & 16.5 \\
削减量 $/(\mathrm{t} / \mathrm{a})$ & 32981.0 & 4122.6 & 628.8 \\
削减率 $/ \%$ & 18.7 & 47.4 & 60.5 \\
\hline
\end{tabular}

\section{3 污染源控制与污染物减排综合系统方案}

3.3 .1 方案目标 以单位 GDP 排放强度法预测 2015 年工业源排放量、结合人口增长和城镇化发展水平 预测城镇生活源排放量和加权平均法预测耕地面 积、畜禽存栏量、水产养殖面积,测算面源污染物排 放量. 设定各污染源治理水平, 分析主要污染治理措 施减排效益, 确定各种污染源的减排潜力,采用线性 规划方法,构建水环境一治污投资费用多目标优化模 型, 依据工程项目样本, 核定费用效益比参数,应用 MATLAB 优化求解, 得到满足最小治理费用取得最 大治污效果的污染减排目标, 确定 2015 年分源削减

量控制目标 (表 2), 污染物分源控制目标以城镇生活源削减为主,削减比例平均占 $80 \%$,城镇生活源污染物 将得到大幅削减, 平均削减率达 $90 \%$ 左右. 依据分源控制目标, 制定研究区工业源削减方案、生活污染源削 减方案、农村面源削减方案, 将总量控制目标落实到具体空间, 最终提出重污染区污染物控制综合系统方 案. 依据方案目标至 2015 年,工业集中处理率至少达 90\% ; 城镇污水、农村生活污水处理率分别达 $97 \%$ 和 $55 \%$ 以上; 畜禽粪便综合利用率达 $90 \%$, 测土配方施肥比例至少达 $85 \%$, 研究区污染物排放总量均达到环境 容量要求, 区域河网水质达标率需达到 $60 \%$ 以上.

表 2 研究区 2015 年污染物排放量及削减量

Tab. 2 The pollutants emission and reduction of study area in 2015

\begin{tabular}{|c|c|c|c|c|c|c|c|c|c|}
\hline \multirow{2}{*}{ 污染源 } & \multicolumn{3}{|c|}{ 预测排放量/(t/a) } & \multicolumn{3}{|c|}{ 削减量/(t/a) } & \multicolumn{3}{|c|}{ 削减率/\% } \\
\hline & COD & 氨氮 & 总磷 & COD & 氨氮 & 总磷 & COD & 氨氮 & 总磷 \\
\hline 工业污染源 & 37475 & 1272 & 227 & 18462 & 1034 & 109 & 49 & 81 & 48 \\
\hline 城镇生活源 & 124007 & 17358 & 1895 & 108628 & 15602 & 1712 & 88 & 90 & 90 \\
\hline 农村面源 & 33561 & 4056 & 584 & 14916 & 1865 & 286 & 44 & 46 & 49 \\
\hline 合计 & 195043 & 22686 & 2706 & 142006 & 18501 & 2107 & 73 & 82 & 78 \\
\hline
\end{tabular}

3.3 .2 污染源控制与污染物减排措施 至 2015 年方案制定以下主要任务,重点实施四大类工程,共 4736 小 项, 总投资约 200 亿元.

1) 工业点源:开展调整产业结构和工业布局、提升废水集中处理能力、实施重点企业提标改造、加强中 水回用建设、推进清洁生产审核和促进工业园区循环经济建设五大类任务,2015 年主要污染物 COD、氨氮、 总磷分别削减 $1.98 \times 10^{4} \mathrm{t} 、 1000 \mathrm{t} 、 100 \mathrm{t}$, 工业废水集中处理率达 $95 \%$ 以上,实现分源确定的目标.

2) 城镇生活源: 加强城镇生活污水处理能力建设, 实施污水处理厂提标改造和加强尾水深度处理及中 水回用措施, COD 、氨氮、总磷分别削减 $108600 \mathrm{t} 、 15600 \mathrm{t} 、 1700 \mathrm{t}$ (表 3 ), 城镇污水集中处理率达 $95 \%$ 以上, 尾 水回用率达到 $40 \%$, 实现分源确定的目标.

3) 农业面源:开展建设农村分散式污水处理设施、实施绿色农业工程、控制畜禽养殖污染、清理整顿水 产围垦养殖共四类重点任务, COD 、氨氮、总磷分别削减分别削减 $1.5 \times 10^{4} \mathrm{t} 、 1.9 \times 10^{4} \mathrm{t} 、 300 \mathrm{t}$, 农村生活污水 处理率达到 $56 \%$,氮肥减施 $20 \%$, 畜禽粪便综合利用率达 $90 \%$, 实现分源确定的目标.

3.3 .3 方案效益与实施效果通过系统方案重点项目的实施, 研究区污染物将得到有效削减, 至 2015 年研 究区需要削减的污染物量分别为 COD $143000 \mathrm{t} / \mathrm{a}$ 、氨氮 $18500 \mathrm{t} / \mathrm{a}$ 和总磷 $2100 \mathrm{t} / \mathrm{a}$ (表 3), 方案实施研究区 97 个镇(街道) 中将有 72 个镇(街道) 污染物排放量能够达到各镇 (街道) 水环境容量要求, 达标率为 $74 \%$, 绝大部分镇 (街道) 污染物排放都能满足环境容量要求, 其中有 20 个镇(街道) 是由于污水厂尾水集中排放, 比重较大不能达标, 加大污水厂中水回用率或对尾水进行进一步净化处理. 同时, 根据河流水质模型进行控 制断面水质达标计算, 方案实施后断面 $\mathrm{COD}_{\mathrm{Mn}}$ 、氨氮和总磷 3 项水质指标超标率呈逐年递减, 至 2015 年 3 项 水质指标超标率分别为 $8.4 \% 、 37.6 \% 、 14.1 \%$, 河网水质平均达标率为 $80 \%$, 河网水质得到有效改善. 
表 3 重污染区污染物削减效益分析

Tab. 3 Analysis of pollutant reduction in seriously polluted area

\begin{tabular}{|c|c|c|c|c|c|}
\hline 年份 & 污染物 & & $\mathrm{COD} /(\mathrm{t} / \mathrm{a})$ & 氨氮/(t/a) & 总磷/ $(t / a)$ \\
\hline 2007 & 基础年排放量 & & 110600 & 11600 & 1500 \\
\hline \multirow[t]{7}{*}{2015} & 预测排放量 & & 195000 & 22700 & 2700 \\
\hline & 削减量 & & 138500 & 16200 & 1900 \\
\hline & 削减能力 & 工业点源污染治理项目 & 19300 & 1000 & 110 \\
\hline & & 城镇生活污水处理项目 & 108600 & 15600 & 1700 \\
\hline & & 农村生活污染治理项目 & 7900 & 1500 & 170 \\
\hline & & 面源污染治理项目 & 7200 & 350 & 130 \\
\hline & & 合计 & 143000 & 18500 & 2100 \\
\hline
\end{tabular}

\section{4 结论}

1 ) 全面调查了重污染区各类污染源以及河网水质, 污染物排放以城镇生活源为主, 工业行业性污染突 出, 农业面源以畜禽养殖污染为主, 14 条主要人湖河流中有 8 条为劣 $\mathrm{V}$ 类水质、 3 条为 $\mathrm{V}$ 类水质、 2 条为 $\mathrm{IV}$ 类 水质、 1 条为 III 类水质, 河流水质主要污染因子依次为氨氮、总磷、高锰酸盐指数.

2) 构建了重污染区套网格水文、水质数学模型, 计算了重污染区水环境容量, 依据污染物削减率与断面 水质超标率的相对误差, 判断水环境容量计算结果合理, 同时基于控制单元水功能区划和各镇区水域面积, 确定了水环境容量分配方法并分配到 97 个镇(街道).

3 ) 基于分镇水环境容量、污染源排放量预测和减排潜力分析, 构建水环境一治污投资费用多目标优化模 型, 确定了分源削减量控制目标, 制订污染源控制与污染物减排综合方案, 实施减排措施, 各镇(街道) 达到 水环境容量要求, 达标率为 $74 \%$, 平均达标率为 $80 \%$, 河网水质得到有效改善可满足功能区水质标准要求.

\section{5 参考文献}

[1 ] 马 倩, 刘俊杰, 高明远. 江苏省人太湖污染量分析 (1998-2007 年). 湖泊科学, 2010,22(1):29-34.

[2] 孟 伟. 中国流域水环境污染综合防治战略. 中国环境科学, 2007,27(5):712-716.

[ 3 ] Davenport TE, Phillips NJ, Kirschner BA et al. The watershed protection approach: a framework for ecosystem protection. Water Science and Technology,1996, 33(4/5) : 23-26.

[ 4 ] 孟 伟. 流域水污染物总量控制技术与示范. 北京: 中国环境科学出版社, 2008:8-19.

[5] 孟 伟, 张 楠, 张 远等. 流域水质目标管理技术研究 ( I ) 一一控制单元的总量控制技术. 环境科学研究, 2008, 21 (2) :35-39.

[ 6 ] 梁 博, 王晓燕. 我国水环境污染物总量控制研究的现状与展望. 首都师范大学学报: 自然科学版, 2004,3 (1): 93-98.

[ 7 ] 张利民, 刘 洋, 孙卫红等. 太湖流域漕桥河小流域水环境容量估算及污染物削减分配. 湖泊科学, 2009, 21 (4): 502-508.

[ 8 ] 《中国环境管理制度》编制组. 中国环境管理制度. 北京:中国环境科学出版社,1991:112-135.

[ 9 ] 鲍 琨, 逢 勇, 孙 瀚. 基于控制断面水质达标的水环境容量计算方法研究一以殷村港为例. 资源科学, 2011, $\mathbf{3 3}(2): 249-252$.

[10] 胡开明,逢 勇,谢飞等. 直湖港、武进港关闸对太湖竺山湖水环境影响. 湖泊科学, 2010,22(6):923-929.

[11] 叶兴平,张玉超. TMDL 计划在污染物总量控制中的应用初探. 环境科学与管理, 2008,33(8): 13-16.

[12] 武进区统计局. 武进区统计年鉴—2008. 北京: 中国统计出版社, 2008:15-46.

[13] 恽东玉. 常州统计年鉴—-2008. 北京: 中国统计出版社,2008:30-66.

[14] 无锡市统计局. 无锡统计年鉴—-2008. 北京:中国统计出版社, 2008:22-53. 